Meta

Journal des traducteurs

Translators' Journal

\title{
Translation Quality Assessment: Linguistic Description versus Social Evaluation
}

\section{Juliane House}

Volume 46, numéro 2, juin 2001

Évaluation : paramètres, méthodes, aspects pédagogiques /

Evaluation: Parameters, Methods, Pedagogical Aspects

URI : https://id.erudit.org/iderudit/003141ar

DOI : https://doi.org/10.7202/003141ar

Aller au sommaire du numéro

Éditeur(s)

Les Presses de l'Université de Montréal

ISSN

0026-0452 (imprimé)

1492-1421 (numérique)

Découvrir la revue

Citer cet article

House, J. (2001). Translation Quality Assessment: Linguistic Description versus Social Evaluation. Meta, 46(2), 243-257. https://doi.org/10.7202/003141ar
Résumé de l'article

L'article présente d'abord trois approches différentes de l'évaluation de la traduction, laquelle prend source dans diverses notions du concept de "sens ", et de son rôle en traduction. On passe ensuite à la description d'un modèle fonctionnel-paradigmatique de l'évaluation de la traduction, lequel distingue plusieurs types de traductions et de versions et souligne l'importance de l'emploi d'un « filtre culturel » dans un certain type de traduction. Ensuite, on procède à l'examen de l'influence de l'anglais à titre de lingua franca internationale sur les procédés traductionnels avant de terminer par un rappel de l'importante distinction à faire entre analyse linguistique et jugement social en évaluation de la traduction ainsi que par l'énoncé de conclusions utiles à la pratique de l'évaluation de la qualité en traduction.
Ce document est protégé par la loi sur le droit d'auteur. L'utilisation des services d’Érudit (y compris la reproduction) est assujettie à sa politique d'utilisation que vous pouvez consulter en ligne.

https://apropos.erudit.org/fr/usagers/politique-dutilisation/ 


\title{
Translation Quality Assessment: Linguistic Description versus Social Evaluation
}

\author{
JULIANE HOUSE \\ University of Hamburg, Hamburg, Germany
}

\begin{abstract}
RÉSUMÉ
L'article présente d'abord trois approches différentes de l'évaluation de la traduction, laquelle prend source dans diverses notions du concept de «sens», et de son rôle en traduction. On passe ensuite à la description d'un modèle fonctionnel-paradigmatique de l'évaluation de la traduction, lequel distingue plusieurs types de traductions et de versions et souligne l'importance de l'emploi d'un «filtre culturel» dans un certain type de traduction. Ensuite, on procède à l'examen de l'influence de l'anglais à titre de lingua franca internationale sur les procédés traductionnels avant de terminer par un rappel de l'importante distinction à faire entre analyse linguistique et jugement social en évaluation de la traduction ainsi que par l'énoncé de conclusions utiles à la pratique de l'évaluation de la qualité en traduction.
\end{abstract}

\begin{abstract}
The paper first reports on three different approaches to translation evaluation which emanate from different concepts of "meaning" and its role in translation. Secondly, a functional-pragmatic model of translation evaluation is described, which features a distinction between different types of translations and versions, and stresses the importance of using a "cultural filter" in one particular type of translation. Thirdly, the influence of English as a worldwide lingua franca on translation processes is discussed, and finally the important distinction between linguistic analysis and social judgement in translation evaluation is introduced, and conclusions for the practice of assessing the quality of a translation are drawn.
\end{abstract}

\section{MOTS-CLÉS/KEYWORDS}

translation quality assessment, meaning, functional-pragmatic model, influence of English, linguistic analysis

\section{Introduction}

How do we know when a translation is good? This simple question lies at the heart of all concerns with translation criticism. But not only that, in trying to assess the quality of a translation one also addresses the heart of any theory of translation, i.e., the crucial question of the nature of translation or, more specifically, the nature of the relationship between a source text and its translation text. Given that translation is essentially an operation in which the meaning of linguistic units is to be kept equivalent across languages, one can distinguish at least three different views of meaning, each of which leads to different conceptions of translation evaluation. In a mentalist view of meaning as a concept residing in language users' heads, translation is likely to be intuitive and interpretative. If meaning is seen as developing in, and resulting from, an externally observable reaction, translation evaluation is likely to involve response-based methods. And if meaning is seen as emerging from larger 
textual stretches of language in use, involving both context and (situational and cultural) context surrounding individual linguistic units, a discourse approach is likely to be used in evaluating a translation.

In this paper I want to first elaborate briefly on these three approaches to translation evaluation; secondly, I will present my own views on the matter, and thirdly and most importantly, I will discuss the often blurred distinction between linguistic description and social evaluation.

\section{Translation Evaluation in Different Schools of Thought}

\subsection{Mentalist Views}

Subjective and intuitive evaluations of a translation have been undertaken since time immemorial by writers, philosophers, and many others, consisting more often than not of global judgements such as "the translation does justice to the original" or "the tone of the original is lost in the translation" and so forth. In a newer guise, such intuitive assessments are being propagated by neo-hermeneutic translation scholars who regard translation as an individual creative act depending exclusively on subjective interpretation and transfer decisions, artistic-literary intuitions and interpretive skills and knowledge. Texts have no core meanings at all, rather their meanings change depending on individual speakers' positions. I will not elaborate here my critique of the hermeneutic position (but see the recent lucid discussion by Bühler 1998), suffice to say that such a relativising stance, and especially the relativisation of "content" and "meaning" is particularly inappropriate for the evaluative business of making argued statements about when, how and why a translation is good.

\subsection{Response-based Approaches}

\subsubsection{Behavioristic Views}

As opposed to subjective-intuitive approaches to translation evaluation, the behaviorist view aims at a more "scientific" way of evaluating translations dismissing the translator's mental actions as belonging to some in principle unknowable "black box." This tradition, influenced by American structuralism and behaviorism, is most famously associated with Nida's (1964) pioneering work. Nida took readers' reactions to a translation as the main yardstick for assessing a translation's quality, positing global behavioral criteria, such as e.g. intelligibility and informativeness and stating that a "good" translation is one leading to "equivalence of response"-a concept clearly linked to his principle of "dynamic equivalence of translation," i.e., that the manner in which receptors of a translation respond to the translation should be "equivalent" to the manner in which the source text's receptors respond to the original. Nida operationalized this equivalence as comprising equal "informativeness" and "intelligibility." Assuming that it is true that a "good" translation should elicit a response equivalent to the response to its original, we must immediately ask whether it is possible to measure an "equivalent response," let alone "informativeness" or "intelligibility." If these phenomena cannot be measured, it is useless to postulate them as criteria for translation evaluation. And indeed, even the most imaginative tests designed to establish verifiable, observable responses a translation presumably 
evokes-using for instance reading aloud techniques, various close and rating procedures-have ultimately failed to provide the desired results, because they were unable to capture such a complex phenomenon as the "quality of a translation." Further, the source text is largely ignored in all these methods, which means that nothing can be said about the relationship between original and translation, nor about whether a translation is in fact a translation and not another secondary text derived via a different textual operation.

\subsubsection{Functionalistic, "Skopos"-Related Approach}

Adherents of this approach (cf. Reiss and Vermeer 19884) claim that it is the "skopos" or purpose of a translation that is of overriding importance in judging a translation's quality. The way target culture norms are heeded or flouted by a translation is the crucial yardstick in evaluating a translation. It is the translator or more frequently the translation brief he is given by the person(s) commissioning the translation that decides on the function the translation is to fulfil in its new environment. The notion of "function," critical in this theory, is, however, never made explicit, let alone operationalized in any satisfactory way. It seems to be something very similar to the real-world effect of a text. How exactly one is to go about determining the (relative) equivalence and adequacy of a translation, let alone how exactly one is to go about determining the linguistic realization of the "skopos" of a translation, is not clear. Most importantly, however, it naturally follows from the crucial role assigned to the "purpose" of a translation that the original is reduced to a simple "offer of information," with the word "offer" making it immediately clear that this "information" can freely be accepted or rejected as the translator sees fit. But since any translation is simultaneously bound to its source text and to the presuppositions and conditions governing its reception in the new environment, Skopos theory cannot be said to be an adequate theory when it comes to tackling the evaluation of a translation in its fundamental bidirectionality.

\subsection{Text and Discourse Based Approaches}

\subsubsection{Literature-oriented Approaches: Descriptive Translation Studies}

This approach is oriented squarely towards the translation text: A translation is evaluated predominantly in terms of its forms and functions inside the system of the receiving culture and literature (cf. Toury 1995). The original is of subordinate importance, the main focus-retrospective from translation to original-being "actual translations," and the textual phenomena that have come to be known in the target culture as translations.

The idea is to first of all attempt to "neutrally" describe the characteristics of that text as they are perceived on the basis of native (receptor) culture members' knowledge of comparable texts in the same genre. However, if one aims at judging a particular text which is plainly not an "independent," "new" product of one culture only, such a retrospective focus seems peculiarly inappropriate for making valid statements about how and why a translation qua translation is as it is. While the solid empirical-descriptive work and the emphasis put on contextualization at the microlevel of the reception situation and the macro-level of the receiving culture at large, 
as well as the inclusion of both a "longitudinal" (temporal, diachronic) and a (synchronic) systemic perspective (considering the polysystemic relations into which the translation enters with other texts in the receiving cultural system), is certainly commendable, the approach does fail to provide criteria for judging the merits and weaknesses of a particular "case." In other words, how are we to judge whether one text is a translation and another one not? And what are the criteria for judging merits and weaknesses of a given "translation text"?

\subsubsection{Post-modernist and Deconstructionist Thinking}

Scholars belonging to this approach (cf. e.g. Venuti 1995) try to critically examine translation practices from a psycho-philosophical and socio-political stance in an attempt to unmask unequal power relations, which may appear as a certain skewing in the translation. In a plea for making translations (and especially translators as their "creators") "visible" and for revealing ideological and institutional manipulations, proponents of this approach aim to make politically pertinent (and "correct") statements about the relationship between features of the original text and the translation text. They focus on the hidden forces shaping both the process of selecting what gets translated in the first place and the procedures that result in the ways original texts are bent and twisted in the interests of powerful individuals and groups "pulling strings" when choosing texts for translation and adopting particular strategies of re-textualization. This is certainly a worthwhile undertaking, especially when it comes to explaining the influence translators can exert through their translation on the receiving national literature and its canon. Further, the application of currently influential lines of thinking such as post-colonial theory (Robinson 1997) or feminist theory (von Flotow 1997) to translation may not be uninteresting in itself. However, if comparative analyses of original and translation focus primarily on the shifts and skewings stemming from ideologically motivated manipulations, and if an agenda is given priority which stresses the theoretical, critical and textual means by which translations can be studied as loci of difference," one wonders how one can ever differentiate between a translation and any other text that may result from a textual operation which can no longer claim to be in a translation relationship with an original text.

\subsubsection{Linguistically-oriented Approaches}

Pioneering linguistic work in translation evaluation includes the programmatic suggestions by Catford (1965), the early Reiss (1971), Wilss (1974), Koller (1979) and the translation scholars of the Leipzig school. In this early work, however, no specific procedures for assessing the quality of a translation were offered. In more recent times, several linguistically oriented works on translation such as e.g. by Baker (1992), Doherty (1993), Hatim and Mason (1997), Hickey (1998), Gerzymisch-Arbogast and Mudersbach (1998) and Steiner (1998) have made valuable contributions to evaluating a translation by the very fact that all these authors-although not directly concerned with translation quality assessment-widened the scope of translation studies to include concerns with linguistics, pragmatics, sociolinguistics, stylistics and discourse analysis.

Linguistic approaches take the relationship between source and translation text seriously, but they differ in their capacity to provide detailed procedures for analysis 
and evaluation. Most promising are approaches which explicitly take account of the interconnectedness of context and text because the inextricable link between language and the real world is both definitive in meaning making and in translation. Such a view of translation as re-contextualization is the line taken by myself in a functional-pragmatic evaluation model first developed some 25 years ago and recently revised (House 1981 and 1997).

\section{A Functional-Pragmatic Model of Translation Evaluation}

\subsection{An Analytic Framework for Analysing and Comparing Original and Translation Texts}

The assessment model (House 1997) is based on Hallidayan systemic-functional theory, but also draws eclectically on Prague school ideas, speech act theory, pragmatics, discourse analysis and corpus-based distinctions between spoken and written language. It provides for the analysis and comparison of an original and its translation on three different levels: the levels of Language/Text, Register (Field, Mode and Tenor) and Genre. One of the basic concepts underpinning the model is "translation equivalence" - a concept clearly reflected in conventional everyday understanding of translation, i.e., the average "normal," i.e., non-professionally trained person thinks of translation as a text that is some sort of "representation" or "reproduction" of another text originally produced in another language, with the "reproduction" being of comparable value, i.e., equivalent. (This is the result of an informal interview study I conducted with thirty native speakers of German support staff as well as medical and economics students at the university of Hamburg). Over and above its role as a concept constitutive of translation, "equivalence" is the fundamental criterion of translation quality. In an attempt to make "a case for linguistics in translation theory," Ivir expresses the inherent relativity of the equivalence relation very well: "Equivalence is...relative and not absolute,...it emerges from the context of situation as defined by the interplay of (many different factors) and has no existence outside that context, and in particular it is not stipulated in advance by an algorithm for the conversion of linguistic units of L1 into linguistic units of L2" (1996: 155).

It is obvious that equivalence cannot be linked to formal, syntactic and lexical similarities alone because any two linguistic items in two different languages are multiply ambiguous, and because languages cut up reality in different ways. Further, language use is notoriously indirect necessitate inferencing to various degrees. This is why functional, pragmatic equivalence - a concept which has been accepted in contrastive linguistics for a long time - is the type of equivalence which is most appropriate for describing relations between original and translation. And it is this type of equivalence which is used in the functional pragmatic model suggested by House (1997), where it is related to the preservation of "meaning" across two different languages and cultures. Three aspects of that "meaning" are particularly important for translation: a semantic, a pragmatic and a textual aspect, and translation is viewed as the recontextualization of a text in L1 by a semantically and pragmatically equivalent text in L2. As a first requirement for this equivalence, it is posited that a translation text have a function equivalent to that of its original which-consisting of an ideational and an interpersonal functional component-is defined pragmatically as the 
application or use of the text in a particular context of situation, the basic idea being that "text" and "context of situation" should not be viewed as separate entities, rather the context of situation in which the text unfolds is encapsulated in the text through a systematic relationship between the social environment on the one hand and the functional organization of language on the other. The text must therefore refer to the particular situation enveloping it, and for this a way must be found for breaking down the broad notion of "context of situation" into manageable parts, i.e., particular features of the context of situation or "situational dimensions": for instance "Field," "Mode" and "Tenor."

Field captures social activity, subject matter or topic, including differentiations of degrees of generality, specificity or "granularity" in lexical items according to rubrics of specialized, general and popular. Tenor refers to the nature of the participants, the addresser and the addressees, and the relationship between them in terms of social power and social distance, as well as degree of emotional charge. Included here are the text producer's temporal, geographical and social provenance as well as his intellectual, emotional or affective stance (his "personal viewpoint") vis a vis the content she is portraying. Further, Tenor captures "social attitude," i.e. different styles (formal, consultative and informal). Mode refers to both the channel-spoken or written (which can be "simple," i.e., "written to be read" or "complex," e.g. "written to be spoken as if not written"), and the degree to which potential or real participation is allowed for between writer and reader. Participation can be "simple," i.e., a monologue with no addressee participation built into the text, or "complex" with various addressee-involving linguistic mechanisms characterizing the text. In taking account of (linguistically documentable) differences in texts between the spoken and written medium, reference is made to the empirically established (corpus-based) oral-literate dimensions hypothesized by Biber (1988). Biber suggests dimensions along which linguistic choices may reflect medium, i.e., involved vs informational text production; explicit vs situation-dependent reference; abstract vs non-abstract presentation of information.

The type of linguistic-textual analysis in which linguistic features discovered in the original and the translation correlated with the categories Field, Tenor, Mode does not, however directly lead to a statement of the individual textual function. Rather, the concept of "Genre" is incorporated into the analytic scheme, "in between," as it were, the register categories Field, Tenor, Mode, and the textual function. Genre thus enables one to refer any single textual exemplar to the class of texts with which it shares a common purpose. The category of Genre is useful for the analysis and evaluation process because, although Register (Field, Tenor, Mode) descriptions are useful for accessing the relationship between text and context, they are basically limited to capturing individual features on the linguistic surface. In order to characterize "deeper" textual structures and patterns, a different conceptualization is needed. This is attempted via the use of "Genre." While register captures the connection between texts and their "microcontext," Genre connects texts with the "macrocontext" of the linguistic and cultural community in which texts are embedded. Register and Genre are both semiotic systems realized by language such that the relationship between Genre, Register and language/text is one between semiotic planes which relate to one another in a Hjelmslevian "content-expression" type, i.e., the Genre is the content plane of Register, and the Register is the expression plane of Genre. Register 
in turn is the content plane of language, with language being the expression plane of Register.

The analytic model is displayed in Figure 1:

\section{INDIVIDUAL TEXTUAL FUNCTION}

\begin{tabular}{|c|c|c|}
\hline REGI & ER & GENRE \\
\hline FIELD & ENOR & MODE \\
\hline Subject matter & $\begin{array}{l}\text { participant relationship } \\
\text { and social action }\end{array}$ & medium \\
\hline & author's provenance & simple/complex \\
\hline & $\begin{array}{l}\text { and stance } \\
\text { participation }\end{array}$ & \\
\hline & $\begin{array}{l}\text { social role relationship } \\
\text { social attitude }\end{array}$ & simple/complex \\
\hline
\end{tabular}

LANGUAGE/TEXT

FIGURE 1

\section{A Scheme for Analysing and Comparing Original and Translation Texts}

Taken together, the analysis yields a textual profile characterizing the individual textual function. Whether and how this textual function can in fact be maintained, depends, however, on the type of translation sought for the original. I distinguish between two types: overt and covert translation, which I will briefly describe in the following section.

\subsection{Two Types of Translation: Overt and Covert Translation}

The distinction between an "Overt Translation" and a "Covert Translation" goes back at least to Friedrich Schleiermacher's famous distinction between "verfremdende" and "einbürgernde" Übersetzungen, which has had many imitators using different terms. What sets the Overt-Covert distinction apart from other similar distinctions and concepts is the fact that it is integrated into a coherent theory of translation criticism, inside which the origin and function of the two types of translation are consistently described and explained. Translation involves text transfer across time and space, and whenever texts move, they also shift frames and discourse worlds. "Frame" is a psychological concept and it is thus, in a sense, the psychological pendant to the more "socially" conceived concept of context, delimiting a class of messages or meaningful actions. A frame often operates unconsciously as an explanatory principle, i.e., any message that defines a frame gives the receiver instructions in his interpretation of the message included in the frame. Similarly, the notion of a "discourse world" refers to a superordinate structure for interpreting meaning in a certain way just as a locutionary act acquires an illocutionary value by reference to an operant discourse world.

Applying the concepts of frame and discourse world to overt and covert translation, we can say that an overtly translated text is embedded in a new speech event, 
which also gives it a new frame. An overt translation is a case of "language mention" (as opposed to "language use"). Relating the concept of "overt translation" to the four-tiered analytical model (Function- Genre- Register- Language/Text), we can state that an original and its overt translation are to be equivalent at the level of Language/ Text and Register as well as Genre. At the level of the individual textual function, functional equivalence, while still possible, is of a different nature: it can be described as enabling access to the function the original has in its discourse world or frame. As this access is to be realized in a different language and takes place in the target linguistic and cultural community, a switch in discourse world and frame becomes necessary, i.e., the translation is differently framed, it operates in its own frame and its own discourse world, and can thus reach at best second-level functional equivalence. As this type of equivalence is, however, achieved though equivalence at the levels of Language/Text, Register and Genre, the original's frame and discourse world are co-activated, such that members of the target culture may "eavesdrop," as it were, i.e., be enabled to appreciate the original textual function, albeit at a distance. In overt translation, the work of the translator is important and visible. Since it is the translator's task to give target culture members access to the original text and its cultural impact on source culture members, the translator puts target culture members in a position to observe and/or judge this text "from outside."

In covert translation, which is a case of "language use," the translator must attempt to re-create an equivalent speech event. Consequently, the function of a covert translation is to reproduce in the target text the function the original has in its frame and discourse world. A covert translation operates therefore quite "overtly" in the frame and discourse world provided by the target culture, with no attempt being made to co-activate the discourse world in which the original unfolded. Covert translation is thus at the same time psycholinguistically less complex and more deceptive than overt translation. Since true functional equivalence is aimed at, the original may be manipulated at the levels of Language/Text and Register via the use of a "cultural filter." The result may be a very real distance from the original. While the original and its covert translation need thus not be equivalent at the levels of Language/Text and Register, they must be equivalent at the levels of Genre and the Individual Textual Function. Schematically, the theoretical distinction between overt and covert translation can be displayed as follows:

FIGURE 2

The Dimension Overt-Covert Translation

\begin{tabular}{|c|c|c|}
\hline Level & \multicolumn{2}{|c|}{ Is strict equivalence the translational goal? } \\
\hline & Overt Translation & Covert Translation \\
\hline Primary level function & NO & YES \\
Secondary level function & YES & N/A \\
Genre & YES & YES \\
Register & YES & NO \\
Language/Text & YES & NO \\
\hline
\end{tabular}


In evaluating a translation, it is thus essential that the fundamental differences between overt and covert translation be taken into account. These two types of translation make qualitatively different demands on translation criticism. The difficulty of evaluating an overt translation is generally reduced in that considerations of cultural filtering can be omitted. Overt translations are "more straightforward," as the original can be "taken over unfiltered," as it were. In evaluating covert translations, the translation assessor has to consider the application of a "cultural filter" in order to be able to differentiate between a covert translation and a covert version.

\subsection{The Concept and Function of a Cultural Filter}

The concept of a "cultural filter" is a means of capturing socio-cultural differences in shared conventions of behavior and communication, preferred rhetorical styles and expectation norms in the two speech communities. These differences should not be left to individual intuition but should be based on empirical cross-cultural research. Given the goal of achieving functional equivalence in a covert translation, assumptions of cultural difference should be carefully examined before interventions in the original's meaning structure is undertaken. The unmarked assumption is one of cultural compatibility, unless there is evidence to the contrary. To take an example, in the case of the German and anglophone linguistic and cultural communities the concept of cultural filter has been given some substance through a number of empirical contrastive-pragmatic analyses, in which anglophone and German communicative priorities along a set of hypothesized dimensions were hypothesized. Converging evidence from a number of cross-cultural German-English studies conducted with different data, subjects and methodologies suggests that there are German preferences for rhetorical styles and conventions of communicative behavior which differ from Anglophone ones along a set of dimensions, among them directness, contentfocus, explicitness and routine-reliance. (cf. House 1996; 1998).

Given the distinction between overt and covert translation, it is obvious that cultural transfer is only possible in the case of overt translation, where cultural items are transported from L1 to L2 acting as a sort of "Verfremdung." In covert translation, however, there is no cultural transfer, but only a sort of "cultural compensation" for L1 cultural phenomena in L2 with the means of L2.

In speaking of a "cultural filter," we need to know, of course, what we mean by "culture." Given widespread postmodernist critiques of culture as an untenable idealization and as something outdatedly relating to the nation state of the nineteenth century, is it today still possible to talk of "the culture" of a language community? Has not the extension of culture to modern complex societies brought about a complexification and problematisation of "culture" which renders it useless as a methodological and conceptual entity? Should we therefore not follow the argumentation by Holliday (1999) who suggested substituting "non-essentialist" "non-reified" "small cultures" for "culture"? Obviously there is no such thing as a stable social group untouched by outside influences and group and personal idiosyncracies, and obviously it is wrong to assume a monolithic unified culture of which all differentness is idealized and cancelled out. Nevertheless, modernist relativation has in practice never yet led to its logical conclusion: the annihilation of research concerned with culture, nor has it prevented researchers from describing cultures as interpretive 
devices for understanding emergent behavior. Further, we cannot ignore the experiences reported by "ordinary" members of a speech community, when they perceive members of another cultural group as behaving "differently" in particular situated discourse events.

\subsection{Distinguishing between Different Types of Translations and Versions}

Over and above distinguishing between covert and overt translation in translation criticism, it is necessary to make another theoretical distinction: between a translation and a version. This distinction is important in view of recent widespread attempts to indiscriminately view intentionally non-equivalent "versions" as translations - even though the new text may have a function different from the original text's function. Producing a version results from a deliberate turning away from the original, a reevaluation and often renunciation of the original. Versions are "freed" to become their own original, particularly in contexts where only intentions of clients and product specifications count, i.e., in highly practice-oriented, mostly technical translation activities, in which considerations of equivalence would only stand in the way of achieving client satisfaction and consumer service. While functionally equivalent covert translations may certainly look like new creations, it is still true that they would not have come into existence if there had not been an original text. And it is important to stress that despite the seemingly cavalier manner with which a translator may have dealt with linguistic correspondences at the word, group and sentence levels (i.e., below the levels of text and discourse), in a covert translation, her actions must be viewed as being subservient to producing correspondences that, each in their different ways, contribute to the overall functional equivalence of the entire translation to its original. This is what makes a translation a translation. It is only when new purposes are superimposed on the translation that a new product, i.e., a version results.

Overt versions are produced in two cases: firstly, whenever a special function is overtly added to a translation text. e.g. to reach a particular audience, as in special editions for children or second language learners with the resultant omissions, additions, simplifications or different accentuations of certain aspects of the original, or popularisations of specialist works designed for the lay public, and secondly, when the "translation" is given a special added purpose. Examples are interlingual versions, resumes and abstracts.

A covert version results whenever the translator-in order to preserve the function of the source text-has applied a cultural filter randomly manipulating the original.

In discussing different types of translations and versions, I do not want to imply, however, that a particular text may be adequately translated in only one particular way. For instance, the assumption that a particular text necessitates either a covert or an overt translation clearly does not hold in any simple way: any text may, for a specific purpose, require an overt translation, i.e., it may be viewed as a text of an "independent value" of its own, e.g. when its author has become, in the course of time, a distinguished figure, in which case the original text acquires the status of a sacrosanct document.

Further, while contrastive pragmatics has certainly made important contributions to assessing covert translations in a non-arbitrary way, it remains a challenge to 
assess the adequateness of applications of a cultural filter. Given the dynamic nature of socio-cultural and communicative norms and the way research necessarily lags behind, translation critics will have to struggle to remain abreast of new developments if they want to be able to fairly judge the appropriateness of changes through the application of a cultural filter in a translation between two given languages. One important new development that affects may social contexts today is the increasing importance of the English language.

\section{English as a Global Lingua Franca in Cultural (Non) Filtering}

With globalisation and internationalisation characterizing much of our life today, there is a concomitant rise in the demand for texts which are simultaneously meant for recipients in many different communities. In other words, ever more texts are needed that are either translated covertly or produced immediately as "parallel texts" in different languages. Until recently translators and text producers tended to routinely apply a cultural filter with which differences in culture-conditioned expectation norms and stylistic conventions were taken into account. However, due to the impact of English as a global lingua franca this situation may now be in a process of change leading to a conflict in translational processes between culture specificity and universality in textual norms and conventions, with "universality" really standing for North European /North American Anglo-Saxon norms. It is this hypothesized change in global translation conventions which has in fact motivated a research project which is presently being conducted in Hamburg inside a larger research undertaking (a Sonderforschungsbereich "Mehrsprachigkeit" funded by the Deutsche Forschungsgemeinschaft). Our main hypothesis in this project is that, instead of using a cultural filter in covert translations or parallel text production, increasingly many culturally universal (or rather culturally neutral translation) texts are created, and a species of "hybrid text" results, which is in reality a carrier of anglophone cultural norms "invading" other linguistic and cultual communities rendering, for example, German texts less content-focussed, more interpersonally oriented, more emotionally involved, more situation-dependent and more concrete, to use Biber's (1988) dimensions of orality vs writtenness in text production, than was the case before.

While the influence of the English language in the area of lexis has long been acknowledged and bemoaned by many linguistic "purists" in Germany and France, anglophone influence at the levels of syntax, pragmatics and discourse has hardly been researched. Rules of discourse, conventions of textualisation and communicative preferences tend to remain hidden, operating stealthily at a deeper level of consciousness and thus presenting a particular challenge for translation evaluation.

In the Hamburg project which examines the influence of English as a lingua franca on covert translations into German (and later into French and Spanish), we are trying out a multi-method approach to translation evaluation, a method which goes beyond the procedure suggested in the assessment model by House (1997). As detailed above, this evaluation model provides for detailed qualitative case-study assessments of the quality of a translation. Just as the much maligned notion of equivalence cannot be taken to provide general guidelines for the translation process, because equivalence derives from the interaction of a particular text and a particular context, so the case-study approach adopted in the functional pragmatic evaluation 
model forbids any facile generalization, simply because the achievement of functional equivalence varies from translation to translation. In the case of covert translation, for example, equivalence must be achieved via the assessment of the specific communicative environments of the two texts and their linguistic correlates. The communicative environments of original and translation must therefore be compared in each individual case, and it is only through amassing evidence of similar textual exemplars that we can approximate generalizations. In order to validate both the hypothesized cross-cultural dimensions that substantiate the cultural filter and the results of the linguistic analysis, introspective methods may be used with which one may tap the translation process. While the evaluation of a translation is primarily product-based it can thus be supplemented or "triangulated" by process-oriented work. Other ways of triangulating the primary analyses include interviews with commissioners of the translation, with editors and other persons involved in the making of a translation. In addition, background documentation, as well as comparisons of translations of the same original into different languages and comparisons of parallel texts and "monolingual" texts belonging to the same Genre can be taken into account. A further extension of the qualitative case-study approach consists of the use of computerised parallel and translation corpora suitable for quantitative analyses.

\section{Linguistic Description versus Social Evaluation in Translation Criticism}

In translation criticism it is important to be maximally aware of the difference between (linguistic) analysis and (social) judgement. In other words, a distinction must be made between describing and explaining linguistic features of the original text and comparing them with the relevant linguistic features of the translation text on the one hand and judging "how good a translation" is on the other hand. Instead of taking the complex psychological categories of translation receptors' intuitions, feelings, beliefs or the (equally vague) effect of a translation as a cornerstone for translation criticism, the functional-pragmatic approach outlined in the above model focusses on texts (validated by introspective accounts of their production). Such an approach, however, cannot ultimately enable the evaluator to pass judgements on what is a "good" or a "bad" translation. Judgements of the quality of a translation depend on a large variety of factors that enter into any social evaluative statement. Critical in the case of translation evaluation is the fact that evaluative judgements emanate from the analytic, comparative process of translation criticism, i.e., it is the linguistic analysis which provides grounds for arguing an evaluative judgement.

As mentioned above, the choice of an overt or a covert translation depends not on the text alone, or on the translator's subjective interpretation of the text, but also on the reasons for the translation, the implied readers, on a variety of publishing and marketing policies, i.e., on factors which clearly have nothing to do with translation as a linguistic procedure because these are social factors which concern human agents as well as socio-cultural, political or ideological constraints and which-in the reality of translation practice-turn out to be often more influential than linguistic considerations or the professiuonal competence of the translator herself. However, it must be stressed that despite all these "external" influences, translation is at its core a 
linguistic-textual phenomenon, and it can be legitimately described, analysed and evaluated as such. It is for this reason that I would argue that the primary concern of translation criticism should be linguistic-textual analysis and comparison, and any consideration of social factors-if it is divorced from textual analysis-must be of secondary relevance in a scientific discipline such as translation studies. Linguistic description and explanation must not be confused with evaluative assertions made solely on the basis of social, political, ethical or individual grounds. It seems imperative to emphasize this distinction given the current climate in which the criteria of scientific validity and reliability are often usurped by criteria such as social acceptability, political correctness, vague emotional commitment or fleeting zeitgeist tastes. If we take translation seriously as an object of scientific inquiry, translation must be seen first and foremost for what it is, namely a phenomenon in its own right: A linguistic-textual operation. And the nature of translation as a linguistic-textual operation should not be confused with issues such as what the translation is for, what it should, might, or must be for.

In approaches to translation criticism such as those squarely oriented towards the purpose and effect of a translation in a new cultural environment, it is unfortunately often the case that no clear line is drawn between translations and other (nonequivalence oriented) multilingual textual operations. One way out of this conceptual (and methodological) confusion seems to be to make a clear distinction between a translation and a version, a distinction which can, as I have tried to show above, only be made if one posits functional equivalence as an incontrovertible criterion for translation.

Translation quality is a problematical concept if it is taken to involve individual and externally motivated value judgement alone. Obviously, passing any "final judgement" on the quality of a translation that fulfills the demands of scientific objectivity is very difficult indeed. However, this should not lead us to assume that translation criticism as a field of inquiry is worthless. As an evaluator one will always be forced to flexibly move from a macro-analytical focus to a micro-analytical one, from considerations of ideology, function, genre, register, to the communicative value of individual linguistic items. In taking such a multi-perspectival viewpoint, a responsible translation critic will arrive at a position where he or she can give a probabilistic reconstruction of the translator's choices, and with the support of the translator's own "voice," be able to throw some light on his or her decison processes in as objective a manner as possible. That this is an extremely complex undertaking which, in the end, yields but approximative outcomes, should not detract us from its usefulness. It is the task of the translation critic to work out, as far as possible, for each individual case, exactly where and with what types of consequences and (possibly) for which reasons (parts of) translated texts are what they are in relation to their "primary texts." Such a modest goal might guard the translation evaluator against making both prescriptive, apodictic and global judgements (of the "good" vs "bad type) that are not intersubjectively verifiable.

In the field of translation criticism, it is unfortunately often the case, that the difference between linguistic analysis and value judgement is ignored when one talks about the quality of a translation. While it is true that both a linguistic and a judgemental component are implicit in translation evaluation, I would caution against mixing them up. I would also caution against using the evaluative component in 
isolation from the linguistic one.

Translation criticism, like language itself, has two basic functions, an ideational function and an interpersonal function. These two functions have their counterpart in two different methodological steps. The first and, in my estimation, the primary one, refers to linguistic-textual analysis, description, explanation, and comparison, and it is based on empirical research and on professsional knowledge of linguistic structures and norms of language use. The second step refers to value judgements, social, interpersonal and ethical questions of socio-political and socio-psychological relevance, ideological stance or individual persuasion. Without the first, the second is useless, in other words, to judge is easy, to understand less so. In other words, in translation criticism we have to make explicit the grounds for our judgement basing it on a theoretically sound and argued set of intersubjectively verifiable set of procedures. A detailed analysis of the "hows" and the "whys" of a translated text (i.e., its linguistic forms and functions) in comparison with the original from which it is derived, is the descriptive foundation for any valid, and argued assessment of whether, how, and to what degree a given translation can be taken to be (more or less) adequate. Clearly, this means recognizing the inevitable subjective part of any translation assessment by a human evaluator. However, this recognition does not invalidate the objective part of the assessment, it merely reinforces its necessity. Making a distinction between empirically motivated linguistic description and socially conditioned grounds for evaluating a translation, as I have tried to do in this paper, may lead us one step further towards solving the puzzling complexity of human translation.

\section{REFERENCES}

BAKer, M. (1992): In Other Words. A Coursebook on Translation, London, Routledge.

Biber, D. (1988): Variation Across Speech and Writing, Cambridge, Cambridge University Press. BüHLER, A. (1998): "Vier Vorurteile über Hermeneutik — Eine Polemik," Hermeneutik und

Naturalismus (B. Kanitschneider und F. J. Wetz, eds), Tübingen, Mohr Siebeck, S. 83-97.

Catford, J. (1965): A Linguistic Theory of Translation, Oxford, Oxford University Press.

Doherty, M. (1993): “Parametrisierte Perspektive,” Zeitschrift für Sprachwisssenschaft, 12, S. 3-38. Flotow, L. von (1997): Translation and Gender, Manchester, St. Jerome.

Gerzymisch-Arbogast, H. und K. Mudersbach (1998): Methoden des wissenschaftlichen Übersetzens, Tübingen, Francke.

Halliday, M. A. K. (1989): Spoken and Written Language, Oxford, Oxford University Press.

— and R. Hasan (1989): Language, Context and Text, Oxford, Oxford University Press.

Hatim, B. and I. Mason (1997): The Translator as Communicator, London, Routledge.

Hickey, L., ed. (1998): The Pragmatics of Translation, Clevedon, Multilingual Matters.

Holliday, A. (1999): “Small cultures," Applied Linguistics, 20, pp. 237-264.

House, J. (1981): A Model for Translation Quality Assessment, 2nd ed., Tübingen, Narr.

- (1996): "Contrastive Discourse Analysis and Misunderstanding. The Case of German and English," Contrastive Sociolinguistics (M. Hellinger and U. Ammon, eds), Berlin, de Gruyter, pp. 345-361.

- (1997): Translation Quality Assessment: A Model Revisited, Tübingen, Narr.

- (1998): "Politeness and Translation," The Pragmatics of Translation (L. Hickey, ed.), Clevedon, Multilingual Matters, pp. 54-72.

— and W. Koller (forthcoming): An Introduction to Translation Theory and Criticism, Amsterdam, Benjamins.

Ivir, V. (1996): “A Case for Linguistics in Translation Theory,” Target, 8, pp. 149-156. 
Koller, W. (1979): Einführung in die Übersetzungswissenschaft, Heidelberg, Quelle und Meyer.

NidA, E. (1964): Toward a Science of Translation, Leiden, Brill.

Reiss, K. (1971): Möglichkeiten und Grenzen der Übersetzungskritik, München, Hueber.

ReIss, K. und H. Vermeer (1984): Grundlegung einer allgemeinen Translationstheorie, Tübingen, Niemeyer.

Robinson, D. (1997): Translation and Empire. Postcolonial Theories Explained, Manchester, St. Jerome.

Steiner, E. (1998): "A Register-Based Translation Evaluation: An Advertisement as a Case in Point," Target, 10, pp. 291-318.

Toury, G. (1995): Descriptive Translation Studies and Beyond, Amsterdam, Benjamins.

Venuti, L. (1995): The Translator's Invisibility. A History of Translation, London, Routledge.

WILss, W. (1974): “Probleme und Perspektiven der Übersetzungskritik," IRAL, S. 23-41. 